\title{
Immunotherapy: A Novel Approach to Fight Cancer
}

\author{
Nidhi Rawat ${ }^{1 *}$, Fateh Singh ${ }^{2}$, Savita Bisen $^{3}$ and Chandrahas Sannat ${ }^{1}$ \\ ${ }^{1}$ Department of Veterinary Microbiology, College of Veterinary Science and A.H., \\ Anjora, Durg, Chhattisgarh, India \\ ${ }^{2}$ National Institute of High Security Animal Disease Laboratory Bhopal, \\ ${ }^{3}$ Department of Veterinary Parasitology, College of Veterinary Science and A.H., \\ Anjora, Durg, Chhattisgarh, India \\ *Corresponding author
}

\section{A B S T R A C T}

Cancer immunotherapy is a type of therapy that uses the body's immune system to prevent, control, and eliminate cancers. The cancer cells on their surface often express the tumor antigens, which are targeted by the immune response components. The past decade has witnessed immunotherapy as an appealing and attractive strategy that established a strong pillar to fight various types of malignancies (Subramaniam et al., 2016). The therapeutic and prophylactic approaches of cancer immunotherapies have been tried against different types of cancers both in human and Veterinary medicine. Beginning with the preventive vaccine for cervical and liver cancer to the first therapy of metastatic melanoma, immunotherapy has already led to major treatment breakthroughs for a number of cancers throughout the world. Currently, the cancer immunotherapy has also become popular in India. Recent success of cancer immunotherapy including monoclonal antibodies, cancer vaccines, adoptive cancer therapy and immune checkpoint inhibitors has revolutionized traditional cancer treatment (Zhang and Chen, 2018). Incorporation of novel immunotherapeutic approaches has the potential to not only improve survival of cancer patients, but also reduce reliance on genotoxic high-dose chemoradiation (Sambi et al., 2019). However, there are many challenges in the way of cancer immunotherapy that will enable to select the rational strategies for overcoming barriers to effective antitumor responses (Dougan et al., 2019). Immunotherapy of cancer is a rapidly evolving field and despite the several obstacles, its current advanced approach has been proved as a potent defensive weapon because of which the deadly diseases like cancers are possible to cure, though not in all, but in many patients.

\section{Introduction}

Cancer immunotherapy is the treatment that is designed to harness the ability of the body's immune system to fight against the cancer. It acts by activating or suppressing the immune system. Immunotherapy which elicits or amplifies an immune response is called as activation immunotherapy, while immunotherapy that reduces or suppresses the immune response is known as suppression immunotherapy. 
Immunotherapies can be categorized as active, passive or hybrid (active and passive). Active immunotherapy directs the immune system to attack tumor cells by targeting tumor antigens. Passive immunotherapies enhance existing anti-tumor responses and include the use of monoclonal antibodies, lymphocytes and cytokines. A wide range of cancers can be treated by various immunotherapy medicines that have been approved in many countries (Korneev et al., 2017).

One of the oldest forms of cancer immunotherapy is the use of BCG vaccine, which was originally to vaccinate against tuberculosis and later was found to be useful in the treatment of bladder cancer (Fuge et al., 2015). The use of monoclonal antibodies in cancer therapy was first introduced with antiCD20 antibody rituximab, and since then such antibodies activate various components of the immune system, they should be considered as potentially immunomodulatory. Apart from classical immunomodulatory receptors, cell surface proteoglycans are an emerging class of targets for cancer immunotherapy (Espinoza-Sanchez and Gotte, 2019).Passive antibody therapies commonly involve the targeting of cell surface receptors and include CD20, CD274 and CD279 antibodies. Once bound to a cancer antigen, the modified antibodies can induce antibody-dependent cell-mediated cytotoxicity, activate the complement system, or prevent a receptor from interacting with its ligand, all of which can lead to cell death.

Active cellular therapies usually involve the removal of immune cells from the blood or from a tumor. Those specific for the tumor are grown in culture and returned to the patient where they attack the tumor. Alternatively, immune cells can be genetically engineered to express a tumor-specific receptor, cultured and returned to the patient. Cell types that can be used in this way are natural killer (NK) cells, lymphokine-activated killer cells, cytotoxic T cells and dendritic cells.

Immunotherapy using cytokines (granulocyte colony-stimulating factor, interferons), imiquimod and cellular membrane fractions from bacteria are licensed for medical use. Moreover, use of interleukins (IL-2, IL-7, IL12), various chemokines, synthetic cytosine phosphate-guanosine (CpG), oligodeoxynucleotides and glucans have been used for immunotherapy in clinical and preclinical studies.

The importance of immunotherapy has been acknowledged by the Nobel prize in physiology and medicine 2018 awarded for the discovery of cytotoxic T-lymphocyte associated protein (CTLA-4) to James P. Allison and programmed cell death protein $1 /$ programmed cell death protein ligand 1 (PD-1 / PD-L1) to TasukuHonjo (Kruger et al., 2019).

Immunotherapy has now become a matter of great interest to researchers, clinicians and pharmaceutical companies, particularly in its application to treat various types of malignancies (Conforti, 2012; Syn et al., 2017). Immunotherapies have been approved in the United States and some other countries to treat a variety of cancers and are prescribed to patients by oncologists. These approvals are the result of years of research and testing designed to demonstrate the effectiveness of these treatments. Immunotherapies are also available through clinical trials, which are carefully controlled and monitored through studies involving patient volunteers.

\section{History of immunotherapy}

Immunotherapy was started back in the 19th century when William B. Coley, who is also the father of immunotherapy, attempted to 
treat an Italian cancer patient who was suffering from 'inoperable' neck tumor. It resulted in the shrinking of the tumor considerably. After that he observed similar cases and injected the mixture of live and inactivated Streptococcus pyogenes and Serratiamarcescens into the patients' tumor.

Immunotherapy vanished after then as Chemotherapy and radio therapy proved themselves to be more successful and it delivered great results. Immunotherapy emerged when Thomas and Burnet first coined the theory of cancer immunesurveillance in the year 1957. Immunotherapy was introduced again as it uses the body's own immunity to fight with the cancerous cells. There are drugs that make the immunity strong and thus its able to fight the cancerous cells.

\section{Activation immunotherapy or immune enhancement therapy}

Therapy of cancer is focused on killing or removing cancer cells and tumors. These therapies are very effective and used against various types of cancers. Cancer immunotherapy attempts to stimulate the immune system to destroy tumors. This therapy uses a person's own peripheral bloodderived natural killer cells, cytotoxic $\mathrm{T}$ lymphocytes, epithelial cells and other relevant immune cells are expanded in vitro and then reinfused (Manjunath et al., 2012).

It has been tested against Hepatitis C ( $\mathrm{Li}$ et al., 2004), Chronic fatigue syndrome (See and Tilles, 1996) and HHV6 infection (Kida et al., 2000). Randomized controlled studies in different cancers resulting in significant increase in survival and disease free period have been reported and its efficacy is enhanced by $20-30 \%$ when cell-based immunotherapy is combined with conventional treatment methods (Syn et al.,
2017).

Topical immunotherapy utilizes an immune enhancement cream (imiquimod) which produces interferon, causing the recipient's killer T cells to destroy warts (van Seters et al., 2008) actinic keratoses, basal cell cancer, vaginal intraepithelial neoplasia (Buck and Guth, 2003), squamous cell cancer (Jarvinen et al., 2009; Davidson et al., 2009), cutaneous lymphoma (Dani and Knobler, 2009) and superficial malignant melanoma (Eggermont and Schadendorf, 2009).

\section{Dendritic cell-based therapy}

Dendritic cells can be stimulated to activate a cytotoxic response towards an antigen. Dendritic cells, a type of antigen presenting cell, are harvested from the person needing the immunotherapy. These cells are then either pulsed with an antigen or tumor lysate or transfected with a viral vector, causing them to display the antigen. Upon transfusion into the person, these activated cells present the antigen to the effector lymphocytes (CD4+ helper T cells, cytotoxic CD8+ T cells and $\mathrm{B}$ cells). This initiates a cytotoxic response against tumor cells expressing the antigen. The cancer vaccine Sipuleucel-T is one example of this approach (Di Lorenzo et al., 2011).

One method of inducing dendritic cells to present tumor antigens is by vaccination with autologous tumor lysates (Hirayama and Nishimura, 2016) or short peptides (small parts of protein that correspond to the protein antigens on cancer cells). These peptides are often given in combination with adjuvants (highly immunogenic substances) to increase the immune and anti-tumor responses.

Other adjuvants include proteins or other chemicals that attract and/or activate dendritic cells, such as granulocyte macrophage 
colony-stimulating factor (GM-CSF). The most common source of antigens used for dendritic cell vaccine in Glioblastoma (GBM) as an aggressive brain tumor were whole tumor lysate, CMV antigen RNA and tumor associated peptides like EGFRvIII (Dastmalchi et al., 2018).

Dendritic cells can also be activated in vivo by making tumor cells express GM-CSF. This can be achieved by either genetically engineering tumor cells to produce GM-CSF or by infecting tumor cells with an oncolytic virus that expresses GM-CSF. Another strategy is to remove dendritic cells from the blood of a patient and activate them outside the body.

The dendritic cells are activated in the presence of tumor antigens, which may be a single tumor-specific peptide/protein or a tumor cell lysate (a solution of broken down tumor cells). These cells (with optional adjuvants) are infused and provoke an immune response.

Dendritic cell therapies include the use of antibodies that bind to receptors on the surface of dendritic cells. Antigens can be added to the antibody and can induce the dendritic cells to mature and provide immunity to the tumor.

Dendritic cell receptors such as TLR3, TLR7, TLR8 or CD40 have been used as antibody targets (Palucka and Banchereau, 2013).

Dendritic cell-NK cell interface also has an important role in immunotherapy. The design of new dendritic cell-based vaccination strategies should also encompass NK cellstimulating potency. It is critical to systematically incorporate NK cells monitoring as an outcome in antitumor DCbased clinical trials.

\section{T-cell therapy}

\section{Adoptive $\mathbf{T}$ cell transfer}

Adoptive $\mathrm{T}$ cell transfer in vitro cultivates autologous, extracted $\mathrm{T}$ cells for later transfusion (Rosenberg et al., 2008). Alternatively, genetically engineered $\mathrm{T}$ cells are created by harvesting $\mathrm{T}$ cells and then infecting the $\mathrm{T}$ cells with a retrovirus that contains a copy of a $\mathrm{T}$ cell receptor (TCR) gene that is specialised to recognise tumour antigens. The virus integrates the receptor into the T cells' genome. The cells are expanded non-specifically and/or stimulated. The cells are then reinfused and produce an immune response against the tumour cells (Morgan et $a l ., 2006)$. The technique has been tested on refractory stage IV metastatic melanomas (Rosenberg et al., 2008) and advanced skin cancer (Hunder et al., 2008).

\section{Chimeric antigen receptor (CAR)-T cell therapy}

CAR-T therapy is the modified immunotherapy in which $\mathrm{T}$ cells are modified to recognize cancer cells in order to more effectively target and destroy them. In this therapy $\mathrm{T}$ cells are harvested from people, genetically alter them to add a chimeric antigen receptor (CAR) that specifically recognizes cancer cells, then infuse the resulting CAR-T cells into patients to attack their tumors. Tisagenlecleucel (Kymriah), a chimeric antigen receptor (CAR-T) therapy, was approved by FDA in 2017 to treat acute lymphoblastic leukemia (ALL).This treatment removes CD19 positive cells (B-cells) from the body (including the diseased cells, but also normal antibody producing cells). Axicabtageneciloleucel (Yescarta) is another CAR-T therapeutic, approved in 2017 for treatment of diffuse large B-cell lymphoma (DLBCL). 


\section{Antibody therapy}

Antibodies are a key component of the adaptive immune response, playing a central role in both recognizing foreign antigens and stimulating an immune response. There are different immunotherapeutic regimens which involve antibodies. Monoclonal antibodies which are generated against specific antigens, such as those present on tumor surfaces, are used to inject into a tumor.

There are two types of antibodies which are used in cancer therapy.

Naked monoclonal antibodies are antibodies without added elements. Most antibody therapies use this antibody type.

Conjugated monoclonal antibodies are combined with other molecule, which is either cytotoxic or radioactive. The toxic chemicals are those typically used as chemotherapy drugs, but other toxins can be used. The antibody binds to specific antigens on cancer cell surfaces, directing the therapy to the tumor. Radioactive compound-linked antibodies are referred to as radiolabelled. Chemolabelled or immunotoxins antibodies are tagged with chemotherapeutic molecules or toxins, respectively (Harding et al., 2010). FDA approved monoclonal antibodies used against different types of cancers are listed in Table 1.

\section{Mechanism of cell death using antibody immunotherapy}

\section{Antibody-dependent cytotoxicity (ADCC)}

cell-mediated

Antibody-dependent cell-mediated cytotoxicity (ADCC) requires antibodies to bind to target cell surfaces. Antibodies are formed of a binding region (Fab) and the Fc region that can be detected by immune system cells via their Fc surface receptors. Fc receptors are found on many immune system cells, including NK cells. When NK cells encounter antibody-coated cells, the latter's Fc regions interact with their $\mathrm{Fc}$ receptors, releasing perforin and granzyme $\mathrm{B}$ to kill the tumor cell. Examples include Rituximab, Ofatumumab, Elotuzumab, and Alemtuzumab.

\section{Complement}

The complement system includes blood proteins that can cause cell death after an antibody binds to the cell surface (the classical complement pathway). Generally the system deals with foreign pathogens, but can be activated with therapeutic antibodies in cancer. The system can be triggered if the antibody is chimeric; as long as it contains the IgG1 Fc region. Complement can lead to cell death by activation of the membrane attack complex, known as complement-dependent cytotoxicity; enhancement of antibodydependent cell-mediated cytotoxicity; and CR3-dependent cellular cytotoxicity. Complement-dependent cytotoxicity occurs when antibodies bind to the cancer cell surface, the $\mathrm{C} 1$ complex binds to these antibodies and subsequently protein pores are formed in the cancer cell membrane (Gelderman et al., 2004).

\section{Cytokine therapy}

Cytokines are proteins produced by many types of cells present within a tumor. They can modulate immune responses. The tumor often employs them to allow it to grow and reduce the immune response. These immunemodulating effects allow them to be used as drugs to provoke an immune response. Two commonly used cytokines are interferons and interleukins (Dranoff, 2004). Interleukin-2 and interferon- $\alpha$ are cytokines, proteins that regulate and coordinate the behavior of the immune system. 


\section{Interleukin}

Interleukins have an array of immune system effects. They have the ability to enhance antitumor activity and thus can be used as passive cancer treatments. Interleukin-2 is used in the treatment of malignant melanoma and renal cell carcinoma. In normal physiology it promotes both effector $\mathrm{T}$ cells and $\mathrm{T}$ regulatory cells, but its exact mechanism of action is unknown (Dranoff, 2004).

\section{Interferon}

Interferons are produced by the immune system. They are usually involved in antiviral response, but also have use for cancer. They fall in three groups: type I (IFN $\alpha$ and IFN $\beta$ ), type II (IFN $\gamma$ ) and type III (IFN $\lambda$ ). IFN $\alpha$ has been approved for use in hairy-cell leukaemia, AIDS-related Kaposi's sarcoma, follicular lymphoma, chronic myeloid leukaemia and melanoma. Type I and II IFNs have been researched extensively and although both types promote anti-tumor immune system effects, only type I IFNs have been shown to be clinically effective. IFN $\lambda$ shows promise for its anti-tumor effects in animal models (Dunn et al., 2006). Unlike type I IFNs, Interferon gamma is not approved yet for the treatment of any cancer. The in vitro study of IFN-gamma in cancer cells is more extensive and results indicate anti-proliferative activity of IFN-gamma leading to the growth inhibition or cell death, generally induced by apoptosis but sometimes by autophagy (Razaghi et al., 2016).

\section{Combination immunotherapy}

Combination of different immunotherapies such as PD1 and CTLA4 inhibitors can enhance anti-tumor response leading to durable responses (Ott et al., 2007). Combining checkpoints immunotherapies with pharmaceutical agents has the potential to improve response, and such combination therapies are a highly investigated area of clinical investigation (Tang et al., 2018). Immunostimulatory drugs such as CSF-1R inhibitors and TLR agonists have been found to be effective in cancer therapy (Perry et al., 2018).

\section{Immune checkpoints}

\section{Combination with chemotherapy}

Traditionally, chemotherapy and radiotherapy were believed to mediate their anti-cancer effect by direct killing of cancer cells. This concept was challenged over a decade ago by Zitvogel and co-workers who discovered that the antineoplastic effect of chemotherapy, in part, depends on the immunogenic cell death of cancer cells. This leads to immune stimulatory signals via activation of the innate immune system through pattern recognition receptors such as toll-like receptor 4 (TLR4) (Apetoh et al., 2007).

Different studies confirmed the immunological effects of chemotherapeutic drugs, in particular, platinum-based agents, and paved the way for the development of combinational regimens using PD-1 / PD-L1blockade together with established chemotherapeutic drugs (Liu et al., 2010; Kruger et al., 2019).

\section{Combination with radiotherapy}

Anecdotal reports on systemic anti-tumor response after irradiation of a single tumor lesion date back more than one century. Regression of non-irradiated lesions after localized radiotherapy of a single lesion was first termed 'abscopal effect' in 1958. The underlying mechanism remained unexplained for a long period and it took almost another 50 years, before Demaria et al., concluded that "Ionizing radiation inhibition of distant 
untreated tumors (abscopal effect) is immune mediated". Nowadays, the causative link between local radiation, immunogenic cell death and systemic tumor response is wellestablished. While the abscopal effect remains a sporadic event, numerous strategies are now under investigation to harness the immunogenic effect of radiotherapy (Kruger et al., 2019).

Immune checkpoints affect immune system function. Immune checkpoints can be stimulatory or inhibitory. Tumors can use these checkpoints to protect themselves from immune system attacks. Currently approved checkpoint therapies block inhibitory checkpoint receptors. Blockade of negative feedback signaling to immune cells thus results in an enhanced immune response against tumors (Pardoll, 2012).

One ligand-receptor interaction under investigation is the interaction between the transmembrane programmed cell death 1 protein (PDCD1, PD-1; also known as CD279) and its ligand, PD-1 ligand 1 (PD-L1, CD274). PD-L1 on the cell surface binds to PD1 on an immune cell surface, which inhibits immune cell activity. Among PD-L1 functions is a key regulatory role on $\mathrm{T}$ cell activities. It appears that (cancer-mediated) upregulation of PD-L1 on the cell surface may inhibit $\mathrm{T}$ cells that might otherwise attack. PD-L1 on cancer cells also inhibits FAS- and interferon-dependent apoptosis, protecting cells from cytotoxic molecules produced by $\mathrm{T}$ cells. Antibodies that bind to either PD-1 or PD-L1 and therefore block the interaction may allow the T-cells to attack the tumor (Granier et al., 2017).

\section{CTLA-4 blockade}

The first checkpoint antibody approved by the FDA was ipilimumab, approved in 2011 for treatment of melanoma (Cameron et al.,
2011). It blocks the immune checkpoint molecule CTLA-4. Clinical trials have also shown some benefits of anti-CTLA-4 therapy on lung cancer or pancreatic cancer, specifically in combination with other drugs (Lynch et al., 2012). However, patients treated with check-point blockade (specifically CTLA-4 blocking antibodies), or a combination of check-point blocking antibodies, are at high risk of suffering from immune-related adverse events such as dermatologic, gastrointestinal, endocrine, or hepatic autoimmune reactions (Postow et al., 2015).

\section{PD-1 inhibitors}

Initial clinical trial results with IgG4 PD1 antibody Nivolumab were published in 2010 (Pardoll, 2012). It was approved in 2014. Nivolumab is approved to treat melanoma, lung cancer, kidney cancer, bladder cancer, head and neck cancer, and Hodgkin's lymphoma (Pollack, 2016). Pembrolizumab is another PD1 inhibitor that was approved by the FDA in 2014. Keytruda (Pembrolizumab) is approved to treat melanoma and lung cancer (Pollack, 2016).

\section{PD-L1 inhibitors}

In May 2016, PD-L1 inhibitor atezolizumabwas approved for treating bladder cancer. Anti-PD-L1 antibodies currently in development include avelumab and durvalumab.

\section{Cancer vaccines}

FDA has approved two cancer vaccines; one for Human Papillomavirus (HPV) causing cervical cancer and another for Hepatitis B virus (HBV) causing hepatocellular carcinoma. Cancer vaccines are a type of immunotherapy that helps the body to fight the disease. In general, vaccines help by 
protecting us from diseases. The vaccines stimulate the immune system. The immune system, then recognises and attacks the foreign substances. In a similar way, cancer vaccines work. The cancer vaccines are made in such a way that, they are able to recognise the proteins that exist on a particular cancer cells. Then, the immune system recognises and attacks the cancer cells. These vaccines help in:

Stopping the growth of cancer Destroying cancer cells that are left behind after any other treatments Preventing cancer from coming back

\section{Types of cancer vaccines}

Further, research is still being carried out by scientists regarding the cancer vaccines. Following are the cancer vaccines which are being researched:

\section{Antigen vaccines}

The antigen vaccines are made out of special proteins called antigens in the cancer cells. Their aim is to boost the immune system to attack the cancer cells.

\section{Dendritic cell vaccines}

Dendritic cell vaccines are produced by growing dendritic cells alongside cancer cells in the laboratory. The vaccine is used to boost the immune system to kill the cancer cells.

\section{Whole cell vaccines}

In this vaccine, whole cancer cell is used and not just the protein to make the vaccine. The advantage of using whole cell over protein is that the cells provide a source of all antigens and thus eliminating the need to figure out the best antigen to target.

\section{Immunotherapy in India}

Immunotherapy does give good results but being a very costly treatment, it scares the patient and they usually wonder whether they will be able to meet the cost of immunotherapy or not.

Good news is the cost of immunotherapy in India is comparatively way too low than countries like US, UK, Australia, etc. The emergence of immunotherapy has brought a ray of hope to the people who are battling with the life - threatening disease like cancer. Every patient in the world has the right to seek the best treatment at the most affordable cost, no matter whether they have to travel to another country for it. India is one of the growing and top - notch medical destination in this new age. Immunotherapy in India is producing high and effective results at the most affordable cost. Now, it is possible to beat cancer with the aid of your own immunity.

Annually, almost two hundred thousand patients come here to seek medical care and a high percentage of them come for cancer treatment. The two leading reason for people coming for cancer treatment like immunotherapy in India is the affordable cost and high level of quality treatment at the best cancer hospitals.

Following is the list of most asked for Cancers in India where immunotherapy is used as a treatment:

1. Bladder cancer

2. Breast cancer

3. Cervical cancer

4. Colorectal cancer

5. Oesophageal cancer

6. Head and neck cancer

7. Kidney cancer

8. Liver cancer

9. Lung cancer 
Other than the above list, following cancers can also be treated using immunotherapy in India. Brain cancer, Leukaemia, Lymphoma, Melanoma, Multiple Myeloma, Ovarian cancer, Pancreatic cancer, Prostate cancer, Sarcoma, Skin cancer and Stomach cancer

\section{Reasons of the preference of immunotherapy in India}

\section{Affordable healthcare}

One major reason that drives the public for immunotherapy in India is the affordable cost of the treatment. India offers very cost effective treatment making it the first choice of most cancer patients looking for immunotherapy.

\section{Acclaimed specialists}

The specialists or doctors in India are highly skilled and experienced. They are known for their extreme knowledge in their field. Further, they have been trained in the best institutes in the world.

\section{Advanced technology}

The technology used in India is highly advanced and is of the same level as compared to any other developed countries. India is counted among the few countries that have the latest technology and treatments like proton therapy, cyber knife radiation therapy, gamma knife, etc.

\section{Services}

The world class services provided in India are available $24 * 7$. Moreover, they are on par with international level. Most of the top hospitals have translators who speak different languages, so as to help the patient to communicate easily with the doctors and hospital staff.

\section{Easy Visa process}

It is easy to get medical visas in India for the people who are suffering from grave diseases. Therefore, it is convenient for the international patients to travel here for quality treatment.

\section{Less waiting time}

Usually, the waiting time is very less, and the patients can start almost immediately their treatment for immunotherapy in India after performing the necessary investigations.

\section{Language}

English is a widely spoken language in the country. This makes it easy for the international patients to communicate without any hassle.

\section{Immunotherapy cost in India}

Immunotherapy cost in India is also costly but its cost is comparatively low and way more economical. The reason of more cost is that India does not have its own drugs to treat immunotherapy and it is a very complex process. One session of immunotherapy costs about 1.3 lakhs to 4 lakhs and one session lasts for 21 days. Immunotherapy in India has been on a successful path since a long time and it keeps on improving day by day.

\section{Benefits and limitations of immunotherapy}

\section{Benefits}

Immunotherapy has been approved in the United States and in some other countries as a first-line of treatment for several cancers, and may also be an effective treatment for patients with certain cancers that are resistant to prior treatment. Immunotherapy may be given alone or in combination with other cancer 
treatments. As of December 2019, the FDA has approved immunotherapies as treatments for nearly 20 cancers as well as cancers with a specific genetic mutation.

1. Immunotherapy may work when other treatments fail. Some cancers (like skin cancer) don't respond well to radiation or chemotherapy but start to go away after immunotherapy.

2. It causes fewer side effects than other treatments. This is because it targets just your immune system and not all the cells in your body.

3. Immunotherapy makes the other cancer treatments work efficiently. For example chemotherapy. Immunotherapy makes the immunity work efficiently so that other treatments can show their positive aspects on the body by killing the harmful cells.

4. When you have immunotherapy, your immune system learns to go after cancer cells if they ever come back. This is called immunomemory, and it could help you stay cancer-free for a longer time.

Table.1 FDA approved antibodies for cancer therapy

\begin{tabular}{|c|c|c|c|}
\hline Antibody & Type* & Target & Approved therapy \\
\hline Alemtuzumab & humanized & CD52 & $\begin{array}{l}\text { B-cell chronic lymphocytic } \\
\text { leukemia }(\mathrm{CLL})\end{array}$ \\
\hline Atezolizumab & humanized & PD-L1 & Bladder cancer \\
\hline Avelumab & human & PD-L1 & Metastatic Merkel cell carcinoma \\
\hline Ipilimumab & human & CTLA4 & Metastatic melanoma \\
\hline Elotuzumab & humanized & SLAMF7 & Multiple myeloma \\
\hline Ofatumumab & human & CD20 & $\begin{array}{l}\text { Chronic myelomonocyticleukemia } \\
\text { (CMML) }\end{array}$ \\
\hline Nivolumab & human & PD-1 & $\begin{array}{l}\text { Metastatic melanoma, Squamous } \\
\text { cell lung cancer, Renal cell } \\
\text { carcinoma, colorectal cancer, } \\
\text { hepatocellular carcinoma, classical } \\
\text { hodgkin lymphoma }\end{array}$ \\
\hline Pembrolizumab & humanized & PD-1 & $\begin{array}{l}\text { metastatic melanoma, squamous } \\
\text { non-small cell lung cancer } \\
\text { (NSCLC), Hodgkin's lymphoma, } \\
\text { Merkel-cell carcinoma (MCC), } \\
\text { primary mediastinal B-cell } \\
\text { lymphoma (PMBCL), stomach } \\
\text { cancer, cervical cancer }\end{array}$ \\
\hline Rituximab & chimeric & CD20 & non-Hodgkin lymphoma \\
\hline Durvalumab & human & PD-L1 & bladder cancer, lung cancer \\
\hline
\end{tabular}




\section{Limitations}

Immunotherapy holds a lot of promise as a cancer treatment. Still, it has certain limitations or side effects.

1. Immunotherapy doesn't always work for every patient, and certain types of immunotherapy are associated with potentially severe but manageable side effects.

2. The area where the medication goes into your body could hurt, itch, swell, turn red, or get sore. Some types of immunotherapy rev up your immune system and make you feel like you have the flu, complete with fever, chills, and fatigue. Others could cause problems like swelling, weight gain from extra fluids, heart palpitations, a stuffy head, and diarrhea. Most of the time, these ease up after your first treatment.

3. Immunotherapy can have an adverse effect on the organs of your body as the drugs are of high power which results in the inefficiency of the organs. This is one of the worst sideeffect of immunotherapy.

Immunotherapy takes time as it is not an easy process. It can definitely treat 4 th stage cancer as well but the time taken by immunotherapy is too long. It forbids the doctors to opt for immunotherapy as it is risky and time taken is too much.

Antibodies may be referred to as murine, chimeric, humanized or human. Murine antibodies are derived from mice and carry a risk of immune reaction. Chimeric antibodies attempt to reduce murine antibodies' immunogenicity by replacing part of the antibody with the corresponding human counterpart, known as the constant region. Humanized antibodies are almost completely human; only the complementarity determining regions of the variable regions are derived from murine sources. Human antibodies have been produced using unmodified human DNA

Cancer immunotherapy is an innovative approach which modulates the immune system to attain prophylactic and / or therapeutic effects against cancer. By restoring the body immune system, immunotherapy increases the longevity of cancer patients. Immunotherapy has become an established pillar of cancer treatment improving the prognosis of many patients with a broad variety of hematological and solid malignancies. FDA has approved several mAbs, vaccines and other immune system components for various types of cancer.Incorporation of novel immunotherapeutic approaches has the potential to not only improve survival of cancer patients, but also reduce reliance on genotoxic high-dose chemoradiation. Challenges in the way of cancer immunotherapy will enable to select the rational strategies for overcoming barriers to effective antitumor responses. Immunotherapy of cancer is a rapidly evolving field and despite the several obstacles, its current advanced approach has been proved as a potent defensive weapon because of which the deadly diseases like cancers are possible to cure, though not in all, but in many patients.

\section{References}

Apetoh L, Ghiringhelli F, Tesniere A, Obeid M, Ortiz C, Criollo A, et al., (2007). Tolllike receptor 4-dependent contribution of the immune system to anticancer chemotherapy and radiotherapy. Nat Med. 13 (9): 1050- 
1059.

Buck HW, Guth KJ (2003). "Treatment of vaginal intraepithelial neoplasia (primarily low grade) with imiquimod 5\% cream". J Low Genit Tract Dis. 7 (4): 290-293.

Cameron F, Whiteside G, Perry C (2011). "Ipilimumab: first global approval". Drugs. 71 (8): 1093-1104.

Conforti, L (2012). "The ion channel network in $\mathrm{T}$ lymphocytes, a target for immunotherapy". Clinical Immunology. 142 (2): 105-106.

Dani T, Knobler R (2009). "Extracorporeal photoimmunotherapy-photopheresis".

Front. Biosci. 14 (14): 4769-4777.

Dastmalchi F, Karachi A, Mitchell D, Rahman M (2018). Dendritic Cell Therapy. eLS. American Cancer Society. pp. 1-27.

Davidson HC, Leibowitz MS, LopezAlbaitero A, Ferris RL (2009). "Immunotherapy for head and neck cancer". Oral Oncol. 45 (9): 747-771.

Di Lorenzo G, Buonerba C, Kantoff PW (2011). "Immunotherapy for the treatment of prostate cancer". Nature Reviews Clinical Oncology. 8 (9): 551561.

Dougan, M., Dranoff, G. and Dougan, S.K. (2019). Immunotherapy: Beyond checkpoint blockade. Annual Review of Cancer Biology. 3: 55-75.

Dranoff G (2004). "Cytokines in cancer pathogenesis and cancer therapy". Nature Reviews. Cancer. 4 (1): 11-22.

Dunn GP, Koebel CM, Schreiber RD (2006). "Interferons, immunity and cancer immunoediting". Nature Reviews. Immunology. 6 (11): 836-848.

Durham SR, Walker SM, Varga EM, Jacobson MR, O'Brien F, Noble W, Till SJ, Hamid QA, Nouri-Aria KT (1999). "Long-term clinical efficacy of grasspollen immunotherapy". N. Engl. J. Med. 341 (7): 468-475.
Eggermont AM, Schadendorf D (2009). "Melanoma and immunotherapy". Hematol. Oncol. Clin. North Am. 23 (3): 547-564.

Espinoza-Sanchez, NA; Götte, M (2019). "Role of cell surface proteoglycans in cancer immunotherapy". Seminars in Cancer Biology. doi:10.1016/j.semcancer.2019.07.012.

Fuge O, Vasdev N, Allchorne P, Green JS (2015). "Immunotherapy for bladder cancer". Research and Reports in Urology. 7: 65-79.

Gelderman KA, Tomlinson S, Ross GD, Gorter A (2004). "Complement function in $\mathrm{mAb}$-mediated cancer immunotherapy". Trends in Immunology. 25 (3): 158-164.

Granier C, De Guillebon E, Blanc C, Roussel H, Badoual C, Colin E, Saldmann A, Gey A, Oudard S, Tartour E (2017). "Mechanisms of action and rationale for the use of checkpoint inhibitors in cancer". ESMO Open. 2 (2): e000213.

Harding FA, Stickler MM, Razo J, DuBridge RB (2010). "The immunogenicity of humanized and fully human antibodies: residual immunogenicity resides in the CDR regions". mAbs. 2 (3): 256-265.

Hirayama M, Nishimura Y (2016). "The present status and future prospects of peptide-based cancer vaccines". International Immunology. 28 (7): 319328.

Hunder NN, Wallen H, Cao J, Hendricks DW, Reilly JZ, Rodmyre R, Jungbluth A, Gnjatic S, Thompson JA, Yee C (2008). "Treatment of metastatic melanoma with autologous CD4+ T cells against NY-ESO-1". N. Engl. J. Med. 358 (25): 2698-2703.

Jarvinen R, Kaasinen E, Sankila A, Rintala E (August 2009). "Long-term efficacy of maintenance bacillus Calmette-Guérin versus maintenance mitomycin $\mathrm{C}$ instillation therapy in frequently 
recurrent TaT1 tumours without carcinoma in situ: a subgroup analysis of the prospective, randomised FinnBladder I study with a 20-year follow-up". Eur. Urol. 56 (2): 260-265.

Kida K, Isozumi R, Ito M (2000). "Killing of human Herpes virus 6-infected cells by lymphocytes cultured with interleukin-2 or -12". Pediatr. Int. 42 (6): 631-636.

Korneev KV, Atretkhany KN, Drutskaya MS, Grivennikov SI, Kuprash DV, Nedospasov SA (2017). "TLR-signaling and proinflammatory cytokines as drivers of tumorigenesis". Cytokine. 89: 127-135.

Kruger S, Ilmer M, Kobold S, Cadilha BL, Endres S, Ormanns S, Schuebbe G, Renz BW, D'Haese JG, Schloesser H, Heinemann V, Subklewe M, Boeck S, Werner J, von Bergwelt-Baildon $\mathrm{M}$ (2019). Advances in cancer immunotherapy 2019 - latest trends. J ExpClin Cancer Res. 38 (1):268. doi: 10.1186/s13046-019-1266-0.

Li Y, Zhang T, Ho C, Orange JS, Douglas SD, Ho WZ (2004). "Natural killer cells inhibit hepatitis $\mathrm{C}$ virus expression". J. Leukoc. Biol. 76 (6): 1171-1179.

Liu WM, Fowler DW, Smith P, Dalgleish AG (2010). Pre-treatment with chemotherapy can enhance the antigenicity and immunogenicity of tumours by promoting adaptive immune responses. Br J Cancer. 102 (1):115123.

Lynch TJ, Bondarenko I, Luft A, Serwatowski P, Barlesi F, Chacko R, Sebastian M, Neal J, Lu H, Cuillerot JM, Reck M (2012). "Ipilimumab in combination with paclitaxel and carboplatin as first-line treatment in stage IIIB/IV non-small-cell lung cancer: results from a randomized, double-blind, multicenter phase II study". Journal of Clinical Oncology. 30 (17): 2046-2054.
Manjunath SR, Ramanan G, Dedeepiya VD, Terunuma H, Deng X, Baskar S, Senthilkumar R, Thamaraikannan P, Srinivasan T, Preethy S, Abraham SJ (2012). "Autologous immune enhancement therapy in recurrent ovarian cancer with metastases: a case report". Case Rep. Oncol. 5 (1): 114118.

Morgan RA, Dudley ME, Wunderlich JR, Hughes MS, Yang JC, Sherry RM, Royal RE, Topalian SL, Kammula US, Restifo NP, Zheng Z, Nahvi A, de Vries CR, Rogers-Freezer LJ, Mavroukakis SA, Rosenberg SA (2006). "Cancer regression in patients after transfer of genetically engineered lymphocytes". Science. 314 (5796): 126-129.

Ott PA, Hodi FS, Kaufman HL, Wigginton JM, Wolchok JD (2017). "Combination immunotherapy: a road map". Journal for Immunotherapy of Cancer. 5: 16.

Palucka K, Banchereau J (2013). "Dendriticcell-based therapeutic cancer vaccines". Immunity. 39 (1): 38-48.

Pardoll DM (2012). "The blockade of immune checkpoints in cancer immunotherapy". Nature Reviews. Cancer. 12 (4): 252264.

Perry CJ, Muñoz-Rojas AR, Meeth KM, Kellman LN, Amezquita RA, Thakral D, Du VY, Wang JX, Damsky W, Kuhlmann AL, Sher JW, Bosenberg M, Miller-Jensen K, Kaech SM (March 2018). "Myeloid-targeted immunotherapies act in synergy to induce inflammation and antitumor immunity". The Journal of Experimental Medicine. 215 (3): 877893.

Pollack A (2016). "F.D.A. Approves an Immunotherapy Drug for Bladder Cancer". The New York Times. ISSN 0362-4331. Retrieved 21 May 2016.

Postow MA, Callahan MK, Wolchok JD (2015). "Immune Checkpoint Blockade 
in Cancer Therapy". Journal of Clinical Oncology. 33 (17): 1974-1982.

Razaghi A, Owens L, Heimann K (2016).

"Review of the recombinant human interferon gamma as an immunotherapeutic: Impacts of production platforms and glycosylation". Journal of Biotechnology. 240: 48-60.

Rosenberg SA, Restifo NP, Yang JC, Morgan RA, Dudley ME (2008). "Adoptive cell transfer: A clinical path to effective cancer immunotherapy". Nature Reviews Cancer. 8 (4): 299-308.

Sambi, M., Bagheri, L. and Szewczuk, M.R. (2019). Current Challenges in Cancer Immunotherapy: Multimodal Approaches to Improve Efficacy and Patient Response Rates. Journal of Oncology. 2019: 1-12.

See DM, Tilles JG (1996). "alpha-Interferon treatment of patients with chronic fatigue syndrome". Immunol. Invest. 25 (1-2): 153-164.

Subramaniam, D.S., Liu, S.V. and Giaccone,
G. (2016). Novel approaches in cancer immunotherapy. Discovery Medicine. 21: 267-274.

Syn NL, Teng MW, Mok TS, Soo RA (2017). "De-novo and acquired resistance to immune checkpoint targeting". The Lancet. Oncology. 18 (12): e731-e741.

Tang J, Shalabi A, Hubbard-Lucey VM (2018). "Comprehensive analysis of the clinical immuno-oncology landscape". Annals of Oncology. 29 (1): 84-91.

van Seters M, van Beurden M, ten Kate FJ, Beckmann I, Ewing PC, Eijkemans MJ, Kagie MJ, Meijer CJ, Aaronson NK, Kleinjan A, Heijmans-Antonissen C, Zijlstra FJ, Burger MP, Helmerhorst TJ (April 2008). "Treatment of vulvar intraepithelial neoplasia with topical imiquimod". N. Engl. J. Med. 358 (14): 1465-1473.

Zhang, H. and Chen, J. (2018). Current status and future directions of cancer immunotherapy. Journal of Cancer. 9: 1773-1781.

\section{How to cite this article:}

Nidhi Rawat, Fateh Singh, Savita Bisen and Chandrahas Sannat. 2020. Immunotherapy: A Novel Approach to Fight Cancer. Int.J.Curr.Microbiol.App.Sci. 9(04): 3058-3071. doi: https://doi.org/10.20546/ijcmas.2020.904.357 